\title{
Litvanya'da Kilim Yapım Özellikleri ve Türk Motiflerinin Etkisi
}

\section{Carpet Weave Art in Lithuania and Influence of}

Galina MișKİNiENE*

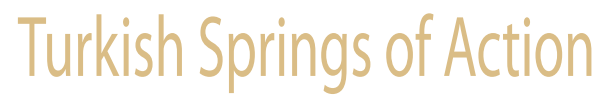

\section{ÖZET}

Litvanya'da dokuma ürünlerinden en yaygın olanı havlu ve yatak örtüleridir. Önceleri nadir olarak rastlanan kilim dokuması XIV. yüzyılda önemli bir yer kazanmaya başlamıştır. Litvan dilinde "kilim" yabancı dillerden alınma kelimelerden birisidir. Litvanya'ya kilimler ilk olarak Avrupa'dan (Italya, Flandra, Fransa) ve Yakın Doğu'dan gelmeye başlamıştır. XV. yüzyılda yerli ustalar dokuma sanatını öğrenmiştir. XVIXVII. yüzyıllarda ise kilim dokuması çok yaygın bir hale gelmiştir. 1578 yılında ilk önce Vilnius'ta daha sonra ise Kaunas şehrinde dokuma atölyeleri kurulmuştur. Litvanya'da kilim dokuması belli bir sürede Türk motiflerinin etkisi altında bulunmaktadır.

Anahtar Kelimeler: Litvanya kilimleri, Türk motifleri, Veselovski'ye ait koleksiyon

Avrupa'daki halkların Türk yapımı kilim ve halılarla tanışması ilk önce İtalya aracılığıyla olmuştur. (1204 yılında) 4. Haçlı seferinden sonra diğer Avrupa devletleri de Türk halıları ve onların özelikleriyle tanışmıştır.

Litvanyalılar'ın dokuma sanatı geleneksel, kendine özgü ve halk gelenekleriyle çok sıkı bağlantılı olarak gelecek kuşaklara taşınmış bir el sanatıdır. Dokuma üzerinde bulunan nakışlar bitki ve hayvanlarla ilgili motiflerdir. Fakat en yaygın ve popüler olanı geometrik desenler ile bitki ve hayvan motiflerinden oluşan karışık desenlerdir.

* Doç. Dr., Litvan Dili Enstitüsü, Farklı Dil ve Kültürler arası İlişkiler Bölümü, P. Vileišio g. 5, Vilnius, Lietuva / LiTVANYA. galina.miskiniene@flf.vu.lt

\section{ABSTRACT}

Towels and bedspreads were most popular among textile production in Lithuania. Carpet weave art in Lithuania has started to develop since XIV century and soon it took important place. In Lithuanian language word "carpet" is borrowing. Carpets came to Lithuania from Italy, Flanders, France and Near East. Since XV century local craftsmen have started to weave carpets. During XVI-XVII centuries carpet weaving became well developed branch of arts and crafts. In 1578 Vilnius' and little bit later Kaunas' weaver manufactories were certified. For some period Lithuanian art of carpets was developing by influence of Turkish patterns.

Key words: Lithuanian carpets, Turkish pattern, Veselovskis' collection.

Litvanya'da dokuma ürünlerinden en yaygın olanı havlu ve yatak örtüleridir. Önceleri nadir olarak rastlanan kilim dokuması XIV. yüzyılda önemli bir yer kazanmaya başlamıştır. Litvan dilinde "kilim" yabancı dillerden alınma kelimelerden birisidir. Litvanya'ya kilimler ilk olarak Avrupa'dan (İtalya, Flandra, Fransa) ve Yakın Doğu'dan gelmeye başlamıştır. XV. yüzyılda yerli ustalar dokuma sanatını öğrenmiştir. XVI-XVII. yüzyıllarda ise kilim dokuması çok yaygın bir hale gelmiştir. 1578 yılında ilk önce Vilnius'ta daha sonra ise Kaunas şehrinde dokuma atölyeleri kurulmuştur.

Litvanya Metrika'da bulunan dokümanlara göre XVII. yüzyıl başlarında Litvanya ve Polonya Cumhuriyetinde dokuma manifaturası Litvanya Büyük Prensliği mareşali Kristupas Veselovski'ye aittir. Kristupas 


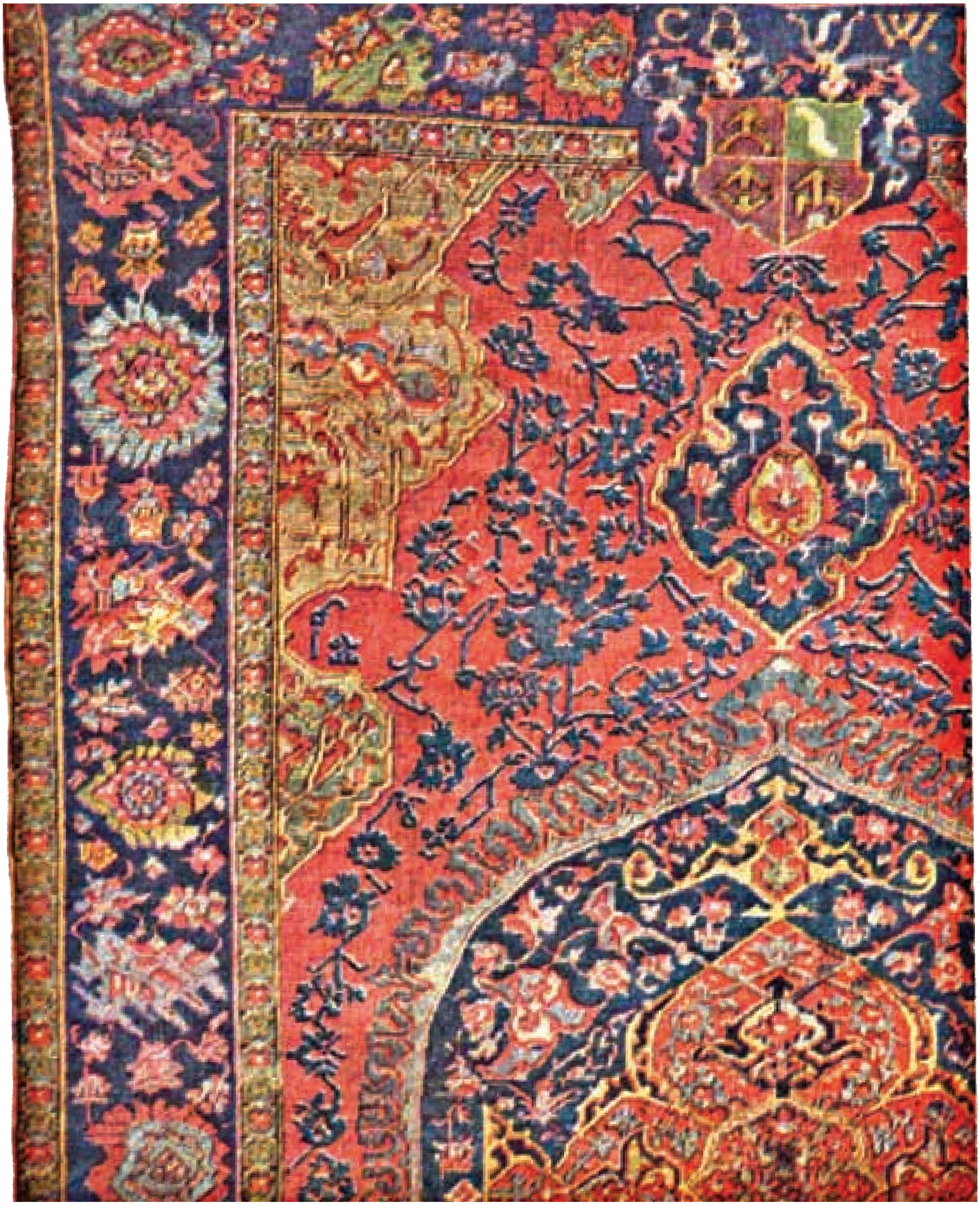

Foto. 1 "Kristupas Veselovski'ye ait damgalı kilim, 1637. Vavel Sarayı, Krokuva”. T. Mańkowski kitabından: Polskie tkaniny i hafty XVI-XVIII w. Wrocław: Zakład imienia Ossolińskich, 1954

Veselovski'nin eşinin vasiyetnamesinden edindiğimiz bilgilere göre " en güzel 24 kilim Türk örneklerine bakarak işlenmiştir" ibaresi bulunmaktadır'. Krokuva Müzesi'nde hala bu kilimlerden biri bulunmaktadır XVII-XVIII. yüzyıllarda feodal sarayı hem doku-

1 T. Mańkowski, Polskie tkaniny i hafty XVI-XVIII w., Wrocław: Zakład imienia Ossolińskich, 1954, s. 71 ma, hem örme kilimler ile süslenmiștir. Bu kilimler Litvanya'ya Kırım, Yakın Doğu, Türkiye ve İran'dan gelmekteymiş. Bu örneklere bakarak yerli Tatar, Karay ve Ermeniler de kilim dokumaya başlamıştır. Örme kilimlerinde daha sık yerel ornömantal olarak adlandırılan figürlere rastlanmaktadır. 
Biz bu makalemizde, Litvanya'da kilim yapım özellikleri ve Litvan kilimlerindeki Türk motiflerinin etkisi üzerinde duracağı

\section{Litvanya Kilimlerinin Tarihi}

Dokunan kilimler hem süsleme hem duvarda asılma ve yerde ısıtma fonksiyonlarını yerine getirmiştir. Yerli kilimler çok renkli olurdu. Kilimlerin dokuma malzemesi olarak, en çok yün ve keten kullanılırdı. Yabancı örneklere bakarak kilimlerde bitki (narçiçeği) ve hayvan (tavus tüyü) motifleri kullanılmıştır. Çeşitli kaynakların verdiği bilgilere göre XVI. yüzyılda kilimler, tablodan daha değerlidir. Mesela Litvanya ve Polonya kralı Sigizmund II. Augustos'un eşi Barbora Radvilaite-Goştautiene, Geranainiai Sarayında özel bir dokumacı bulundururdu. Kraliçenin emriyle 1544 yılında bu dokumacı Goştautas ailesi için damgalı bir kilim dokumuştu. Kilimin rengi yeşildi. Kral Sigizmund II. Augustos'un kendisi de kilimlerden çok hoşlanıyormuş. 1544 yılında Krokuva'dan Vilnius Sarayına kilimlerin büyük bir koleksiyonu yollanmıştır. 1548 yılında 'Adam ve Havva' temalı bir koleksiyon yine Brüksel'den sipariş edilmiştir. Dokümanlara göre Grandükün özel bir dokumacısı Rodrikas Dermoinas'tır².

Yine 1553 yılında Litvanya Büyük Prensliğinin kalem müdürü Radvila Juodasis (Kara Radvil)'in sarayında ünlü Alman sanatçı Lukas Kranach tarafından yapılmış 'Hazreti İsa'nın Ürdün'de vaftizi' adlı tabloya göre dokunmuş bir kilim vardır. Aynı zamanda bu kilimde, reformculardan Martin Liuter ve Jona Fridrich'nin portresi de kullanılmıştır.

XVI. yüzyılın ikinci yarısında kilimler, saray ve kiliselerin defterlerinde de tespit edilmiştir. XVI. yüzyılın son çeyreğinde, veznedar yardımcısı D. Chaleckis'a ait iki tematik kilim koleksiyonu bulunur. Birincisi avlanma sahneleri, ikinci ise İncil'den Samson ile ilgili sahneleri içermektedir. Kilimlerin manzarası, bordürleri Flandra ustalarının yapmış olduğu kilimlerin manzarasına ve bordürlerine benzetilmiştir

XVII. yüzyılın birinci çeyreğinde, prenses Zavişaite'ye ait 'Credo' ve 'Evanjelist' adlı iki tematik kilim koleksiyonu vardı. Her iki koleksiyondaki kilimler Zavişa ve Kesgaila ailesinin damgalarıyla vurgulanmıştır. Bu bahsettiğimiz kilimlerde en sık kullanılan renkler mavi, yeşil ve kum rengidir.

En yaygın olan kilimler dekoratif ornömantal kilimlerdir. XVI. yüzyılda Ukrayna'daki saray ve kiliselerde bulunan bu kilimlere 'Litvanya'da dokunmuş kilimler' ya da sadece 'Litvanya kilimleri' denmiştir. Bu kilimlerin çoğu saraydaki atölyede dokunmuştur. Bu kilimler sadece duvarlara değil, masa, iskemle ve san-

2 A.g.e., s. 88 dıklara da örtülmüştür. Yemek vakitlerinde, kilimlerin üstüne yine işlenmiş havlu örtülmekteydi.. Böylece bu kilimlerin arkası çoğu zaman tek renk ya da ornömantal oluyormuş. Bazıları Şarkiyat dokunma nakışlarına bakarak yapılmıştır. Bu kilimlere ‘Türk kilimleri’ denmiştir ${ }^{3}$. Türk kilimlerinin fonu çoğu zaman vişne rengi ve yeşil konturludur. Desen olarak sekizgen rozas ya da yıldızlar ile stilize edilmiş çiçek demetleri bu kilimlerdeki en önemli süslemelerden biridir. Mesela Krokuva Müzesi'nde saklanan bu kilimlerden birisi düz bitki ornömental süslenmiş, ornöment kompozisyonu simetrik, stilize ve dokunma tarzı doğu özellikleri taşır. Sadece bordürün yukarısında Rönesans dönemine ait motiflerle süslenmiş bir damga bulunmaktadır.

XVII. yüzyılda dokuma atölyeleri sadece yerli pazara değil yurt dışı pazarlara da kilim dokumaya başlamıştır. 1623 yılında Vilnius'ta çalışan çok yetenekli dokuma ustalarından biri J. Litvinkeviçius. XVII-XVIII. yüzyıllarda en önemli kilim dokuma manufaktürlerinden olan Bartininku (Vilkavişkis ili), Alytus ve Şiauliai'den bahsetmek gerekmektedir. Manufaktürlerin kurucuları coğu zaman Litvanya saray adamları oluyormuş. Mesela Oginskiai, Kaişiadoriai iline bağl. Muro Strevininkuose'de, Radvilai ise Moletai iline bağlı Kedainiai ve Dubingiai'de yeni fabrikalar kurmuştu. Bu fabrikalara projeleri çoğu zaman yabancı ustalar hazırlıyordu. Nadiren yerli Vilniuslu ustalar da bu işlere katılıyordu.

$\mathrm{Bu}$ yüzyıllarda dokunan kilimler sık bitki ve nadir geometrik ornömentiyle süslenmiştir. Kilim desenleri çoğu zaman şakuli olarak ve ince çiçekli etrafı çevrilmiş olarak görünmektedir. XVII-XVIII. yüzyıllarda halk örtme kilimlerinde (düğünde çeyiz olarak dokunmuş) çiçek, yaprak, saksılı çiçek ve bordürdeki figürlerle dolu motiflere sık sık rastlanmaktadır. XVIII. yüzyılda örme kilimleri Radvilai ve Oginskiai fabrikalarında dokunmaya başlanmıştır. Radvilai ailesindeki örme kilimleri, aileye özgü damgalarla süslenmiştir. Oginskiai kilimleri ise stilize edilmiş bitki ya da halk ve basit Yakın Doğu ornömentiyle ayrılmıştır. Kilim fonu çoğu zaman natürel yün rengindedir. Desenin solgun görünmesi için kahverengi, siyah ve beyaz renkleri kullanılmıştır.

XVIII. yüzyılın sonunda kilim tertibi ve ornömanı çok yavaş değişmiştir. Genellikle Fransa üslubu takip edilmiştir. Leh üslubuna ve oradaki Fars kilimlerinin yuvarlak çerçeveli kabartmasına da özenilmiştir. Desende merkezcil yapı yer almıştır. Kilim ortasında simetri olarak stilize edilmiş desen, renklerin kontrastı ve bitkisel motiflerle dolu bordürler yer alır. Yavaş yavaş doğu

3 T. Adamonis, K. Čerbulenas, Lietuvos TSR dailés ir architektūros istorija, T. I. Vilnius: Mokslas, 1987, p. 189. 
desenleri ve doğu yapısının natürelliğine doğru bir gidiş vardır. Kilimlerin ortasında sepette çiçek, fiyonga bağlanmış çiçek demetleri, çiçek çelengi bulunmuştur ${ }^{4}$

XIX. yüzyılda kilim dokuması epeyce azalmıştır. 1831 yılından sonra sadece Eidringeviçius fabrikası açık kalmiştır. Bu fabrikada dokunan kilimlerin deseni tam Avrupa tarzıdır. Kilimlerin rengi natüreldir. 1840 yılında V. Lopacinskio kilim fabrikası açmıştır ${ }^{5}$. Burada üretilen kilimler hakkında sadece çok renkli olduklarını biliyoruz.

XIX-XX. yüzyıllarda kilim sanatı pek az değişim gösterir. Daha çok kilimin ev içi uyumuna özen gösterilmiştir. Bitki ve hayvan motifleri yerine geometrik motifler tercih edilir. Duvar kilimleri, yer kilimlerden daha renkli ve karışık desenlidir.

\section{Litvanya Kilimlerinde Doğu Motifleri}

Örme kilimlerin yayılması İslam kültürüyle bağlantılıdır. XV. yüzyılda Doğudan Avrupa'ya gelen kilimler özel hallerde kullanılan bir görünüm almıştır. XV. yüzyılda yerli ustaların dokuma sanatını öğrenmesiyle beraber üretimde Doğu üslubu kullanmıştır. Litvanya topraklarında Doğu etkisiyle dokunmuş kilimlerden en çok bilineni örnek olarak yukarıda bahsettiğimiz Kristupas Veselovski'ye ait bir kilimdir. Tahminlere göre, bu kilimi Ermeni asıllı Murat Jakuboviç dokumuştur 6 . Elbette o zamanlarda bu bilinen tek kilim değildir. Çeşitli rivayetlerde Fars kilimlerinin yanında 'divonai' adıyla bilinen kilimlerden de bahsedilmiştir. 'Divonai' yerli terminolojiye göre Türk kilimleri demektir. Demek ki, hem yerli Doğu etkisiyle yapılmış hem ithal edilmiş kilimler Litvanya'da tanınmaktadır. İlk dönem Litvanya ve Polonya kilim dokumalarında görülen dış etkiler üzerine Polonyalı araştırmacılar Tadeusz Mańkowski ve Ksawery Piwocki pek çok araştırma yapmıştır ${ }^{7}$ Kilim dokuma aşamasında, yerli ustalar Doğu üslubuna bakmış ancak kendilerine ait motifleri koymaya cesaret edememişlerdir.

Litvanya Büyük Prensliğinde Doğu etkisiyle yapılmış en güzel kilimler yurt dişında bulunmuştur. Bu kilimlere Londra'daki Viktoriya ve Albert Müzesi, Paris'teki Sanat Müzesi ve özel koleksiyonlarında rastlanmaktadir (Foto. 2).

4 T. Adamonis, N. Adomonytè, Lietuvos dailès ir architektūuros istorija, T. II. Vilnius: Vilniaus dailès akademijos leidykla, 1997, p. 272.

5 A.g.e., s. 273

6 R.R.Trimonienè, "Rytietiški ir lietuviški motyvai Lietuvos Didžiosios Kunigaikštystės rištiniuose kilimuose", Rytų Europos kultūra migracijos kontekste. Tarpdalykiniai tyrimai. Merkienė Irena Regina (ed.) Versus Aureus, 2007, p. 517.

7 T. Mańkowski, Polskie tkaniny i hafty XVI-XVIII w., Wrocław: Zakład imienia Ossolińskich, 1954; Sztuka tkacka w Polsce. Dawna i wspótczesna. Katalog wystawy: wstęp T. Mańkowskiego, Warszawa, 1938; Tkanina Polska, pod red. Prof. K. Piwockiego, Warszawa: Arkady, 1959.

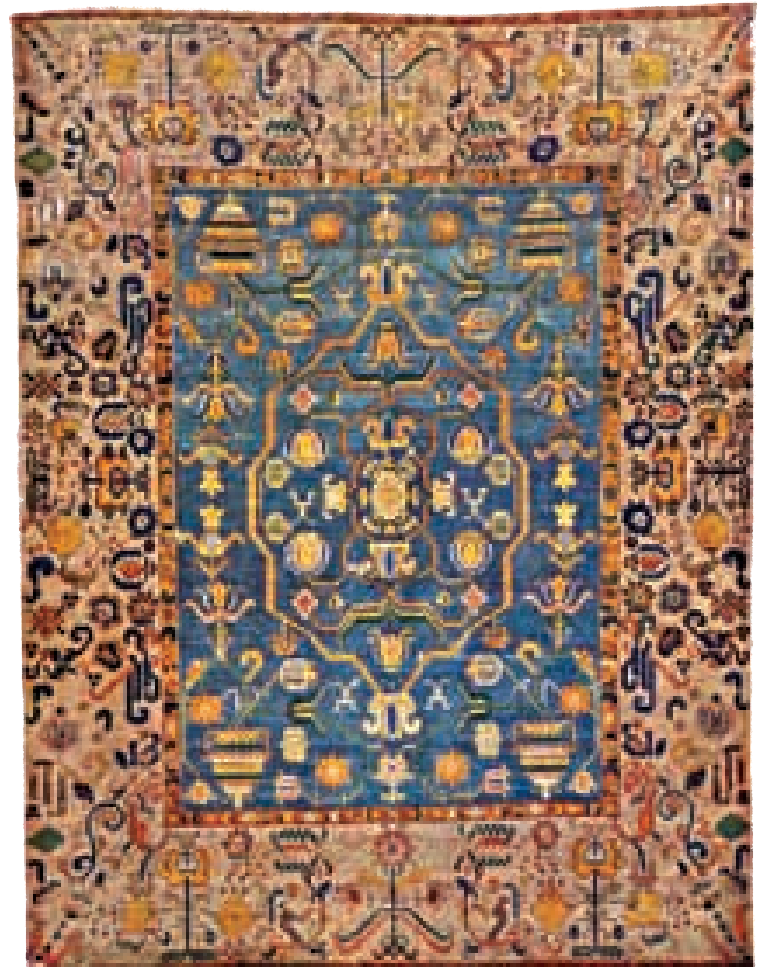

Foto. 2 "Kilim XVIIII. yüzyıl Londra'daki Viktoriya ve Albert Müzesi". T. Mańkowski kitabından: Polskie tkaniny i hafty XVI-XVIII w. Wrocław Zakład imienia Ossolińskich, 1954

XVII. yüzyılda bilinen üç fabrikadan (birincisi K. Veselovski'ye ait - Tykocin, Suraj ve Bialystok; ikincisi ise Stanislav Koniecpolski'ye ait - Broday; üçüncüsü - sahibi ve yeri bilenmeyen bir fabrika) 1. ve 2 . fabrikalarda kilim dokunmuştur. Broday fabrikasında XVII. yüzyılın sonları ile XVIII. yüzyılın başlarında Türk dokumacılar da çalışmıştır.

XVII. yüzyılın ikinci yarısında Litvanya ve Polonya'da dokunmuş kilimlerde tam Doğu üslubu tutmamaya başlamıştır. 'Doğu' motifleri yanında barok deseni de görülmektedir. Çoğu Zaman Doğu geometrik ornöment Avrupa'da yaygınlaşan detaylarla (saksılı çiçek, bolluk boynuzu, çiçek çelengi) karışmıştır. XVIII. yüzyılın başlarında Broday fabrikasında Doğu üslubuyla dokunmuş kilimler vardı. Örnek olarak Krokuva'da, Vavel Sarayı koleksiyonunda saklanan Potocki ve Mnişka ailesi damgalı kilimlerden bahset-

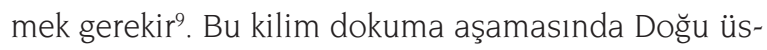
lubundan tam olarak vazgeçilmemiş, sadece bu üslup sadeleştirilmeye çalışılmıştır. Folklor ve halka ait desenleri natürel olarak İslami anlamı kaybedilmiş sembollerle karıştırılmıştır. Bu dokuma meyli XVIII. yüzyıl

8 R.R.Trimonienè, "Rytietiški ir lietuviški motyvai Lietuvos Didžiosios Kunigaikštystės rištiniuose kilimuose", Rytų Europos kultūra migracijos kontekste. Tarpdalykiniai tyrimai. Merkienė Irena Regina (ed.) Versus Aureus, 2007, p. 519.

9 A.g.e., s. 520 
boyunca Oginskis ve Radvilas'a ait açılmış yeni fabrikalarla beraber daha da artırılmıştır. Her iki fabrikada dokunan kilimlerde orijinal Doğu ve yerli özelliklerine sık rastlanmaktadır. Burada stilize edilmiş ve geometrik Yakın Doğu desenleri kendisine yer bulmuştur. Kilimlerde Doğu desenlerinin yanında, Litvanya halk dokuma ve nakış unsurları yer almıştır. Halk nakışları arasında ikili kuş, ortasında bulunan rozet çerçevesinde saksıll çiçek en popülerdir (Foto. 3).

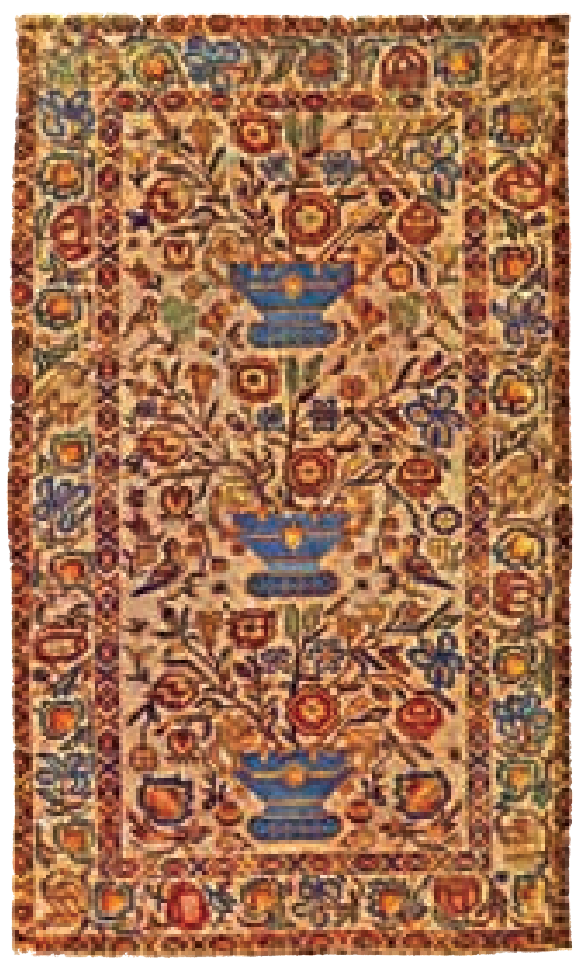

Foto. 3 "XVIII. yüzyıl saksılı çiçekle süslenilmiş kilim. Vavel Sarayı, Krokuva". T. Mańkowski kitabından: Polskie tkaniny i hafty XVI-XVIII w Wrocław: Zakład imienia Ossolińskich, 1954

XVIII. yüzyılın sonunda ve XIX. yüzyılda dokuma kilimlerinde Doğu desenlerinin yanında Fransa'dan gelen üslup da yer almaktadır. Bu üslupla en çok dokunmuş kilimler Antanas Tyzenhauzas'a (17331785) ait fabrikadan çıkmıştır. Bu kilimlerin özellikleri pastel renklerle yapılan desenler ve natürel bitkisel motiflerle dolu kilim kompozisyonu içerir. Bu üstün olan üsluba 'Tyzenhauzas üslubu' ya da 'Fransa tarzı' deniri ${ }^{10}$. XIX. yüzyılın sonunda Doğu üslubunun kalmamış olduğunu söyleyebiliriz.

\section{Sonuç}

Litvanya topraklarına XIV. yüzyılda gelen kilim dokuma geleneği yıllar boyunca çok değişmiştir. Kilim dokuma geleneği üç döneme ayrılmıştır:
1. XV. -XVI. yüzyıl dokuma sanatında Fars kilimlerinin desenleri ve motifleri tam olarak tüm yapısıyla yerli ustalara örnek olmaktaydı. Bu üsluba sıkı bir şekilde bağlı olmuş ve her hangi bir değişiklik yapılmamıştır. XVII. yüzyıl döneminde Fars örnekleri yerine Türk denilen örnekler gelmektedir.

2. XVII. yüzyılın ikinci yarısından başlayarak Doğu desenleri ve yerli halka ait dokuma desenleri birbirine karışmaya başlamıştır. Yüksek sosyete tarafından getirilen Doğu modası ile yerli gelenek karışmış ve özel bir yerli üsluba yol açmıştır (Foto. 3). Niçin bu üslübun tercih edildiği hala bilinmemektedir. Stilize edilen folklor motifleri yıllar boyunca bazen kuvvetli bazen ise hafif derecede olmaktaydı. Litvanya'da kilim dokuma geleneği bir taraftan Yakın Doğu öbür taraftan Avrupa'dan gelen etki altında gelişmiştir.

3. XVIII. yüzyılın ikinci yarısı ile XIX. yüzyılda 'Fransa tarzı' denilen bir dönem başlamıştır (Foto. 4). Bu dönemde Avrupa'daki en güzel örneklere bakılarak natürel motifler tercih edilmiştir. Fakat XVIII. yüzyılın sonunda sadeleştirilmiş, Doğu üslubuna da bir dönüş olmuştur. XIX. yüzyılda kilim üretimi azalmış, 1831 yılından sonra sadece Eidrıgevıçius ve 1840 yılında açılan Lopacinskio kilim fabrikaları çalışmaya devam etmiştir ${ }^{11}$.

Litvanya'da kilim yapım özellikleri ve Türk motiflerinin etkisi üzerine yapılmış araştırmalar yeni sayılmaktadır ${ }^{12}$. Litvanya toprakları tarihsel olarak eskiden beri Polonya, Beyaz Rusya ve Ukrayna topraklarıyla yakın ilişki içindedir. Bu topraklar için kilim dokumasının oluşturulma sebepleri ve özellikleri aynı görünmektedir ${ }^{13}$. Bilim ve sanat koruyucuları hem Litvanya hem Beyaz Rusya topraklarında kilim fabrikaları kurmuştur. Farklı dönemlerde en ünlü ve başarılı olanları K. Veselovski, S. Koniecpolski, Radvilas, Oginskis ve A. Tyzenhauzas'a ait kilim dokuma fabrikalarıdır.

11 T. Adamonis, N. Adomonytè, Lietuvos dailés ir architektūros istorija, T. II. Vilnius: Vilniaus dailės akademijos leidykla, 1997, p. 273.

12 Litvanya sanatı ve mimarlığı hakkında bilgi veren kitap ve makalelerde bu konu sadece birkaç cümleyle zikredilmiştir. Litvanya'da kilim yapım özellikleri ve Türk motiflerinin etkisi üzerinde yapılmış çalışmalardan bahsederken Trimonienė Rita Regina'nın "Rytietiški ir lietuviški motyvai Lietuvos Didžiosios Kunigaikštystės rištiniuose kilimuose" makalesinden ve Ringelienè Lina'nın Kilimai: austiniu ir rištiniu kilimu istorija: mokomoji priemone, (Vilniaus pedagoginio universiteto leidykla, 2010) adlı eserinden de bahsetmek gerekmektedir.

13 Karaneuskaya İrına, "Rukatvornasst, zgornutaya gistorıyay", Mastatstva 11 (227), Minsk, 2001, s. 34-42. 


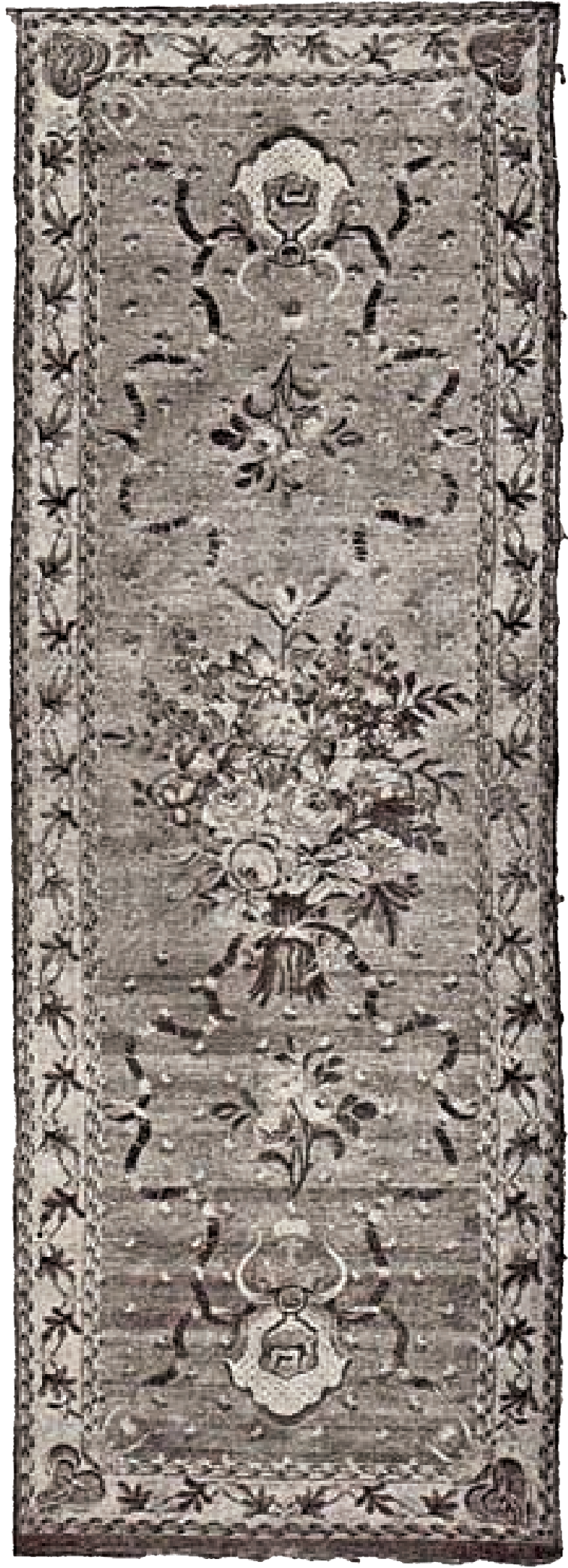

Foto. 4 “Antanas Tyzenhauzas'a ait kilim, XVIII. yüzyılın ikinci yarısı. Vavel sarayı, Krokuva”. T. Mańkowski kitabından: Polskie tkaniny i hafty XVI-XVIII w. Wrocław: Zakład imienia Ossolińskich, 1954
R. Trimoniene'in tahminine göre: 'Üslubun değişmesi, Doğu etkisi ve yerel halka ait nakış motiflerinin karışımı belki makul ölçüde oldu. Böylece özel ve sadece Litvanya ustalarına ait bir tarz doğmuştur'14. Fakat araştırmacının kendisi bugün bile daha net cevap veremiyor, çünkü bu konu hala az araştırılmış durumdadır. Litvanya ve Türk dokumalarında benzeşen veya ayrışan motifler üzerinde ileride yapılacak olan ilmi araştırmalarla belki bu sorulara cevap verilebilir. Bu konularda yapılacak olan çalışmaların iki kültür arasındaki sosyoloji, tarih ve sanat tarihi alanlarındaki ilişkilerin ortaya çıkarılması açısından çok önemli olacağını söyleyebiliriz.

\section{Kaynaklar}

Adamonis Tadas, Adomonyte Nijolè, Lietuvos dailès ir architektūros istorija, T. II. Vilnius: Vilniaus dailès akademijos leidykla, 1997.

Čerbulènas Klemensas, Lietuvos TSR dailés ir architektūuros istorija, T. I. Vilnius: Mokslas, 1987.

Balčikonis Juozas, Audinių raštai, Vilnius: Valstybinė politinès ir mokslinès literatūros leidykla, 1961.

Johansenas Rudolfas Brobis, Menas ir mes, Vilnius: Vaga, 1975.

Jurginis J., Lietuvos meno istorijos bruožai, Vilnius: Valstybinė grožinès literatūros leidykla, 1960.

Hołubeć Mykoła, Kilim Ukraiński. Wystawa druga. Lwów: Z drukarni Naukowego Tow. im. Szewszenki we Lwowie, maj 1936.

Karaneuskaya İrına, "Rukatvornasst, zgornutaya gistorıyay", Mastatstva 11 (227), Minsk, 2001, s. 34-42.

Kayıpmaz Fahrettin, Kayıpmaz Nacine, Genç Mustafa, Tarihten günümüze Bergama halıları, Bergama Belleten, 10, 2001.

Mańkowski Tadeusz, Polskie tkaniny $i$ hafty XVI-XVIII w., Wrocław: Zakład imienia Ossolińskich, 1954.

Ringelienè Lina, Kilimai: austiniu ir rištiniu kilimu istorija: mokomoji priemonè, Vilnius: Vilniaus pedagoginio universiteto leidykla, 2010.

Tkanina Polska, pod red. Prof. K. Piwockiego, Warszawa: Arkady, 1959.

Trimonienė Rita Regina, "Rytietiški ir lietuviški motyvai Lietuvos Didžiosios Kunigaikštystès rištiniuose kilimuose", Rytu Europos kultūra migracijos kontekste. Tarpdalykiniai tyrimai. Merkienè Irena Regina (ed.) Versus Aureus, 2007, pp. 514-529.

Sztuka tkacka w Polsce. Dawna i wspótczesna. Katalog wystawy: wstęp T. Mańkowskiego, Warszawa, 1938. 